\title{
Impact of attitudes and beliefs on antiretroviral treatment adherence intention among HIV-positive pregnant and breastfeeding women in Zambia
}

\author{
Jerry John Nutor ${ }^{1 *} \mathbb{D}$, Jaime C. Slaughter-Acey ${ }^{2}$, Shannon P. Marquez ${ }^{3}$, Rose Ann DiMaria-Ghalili',
} Florence Momplaisir ${ }^{5}$, Kelechi Elizabeth Oladimeji ${ }^{6}$ and Loretta S. Jemmott ${ }^{4}$

\begin{abstract}
Objective: The aim of this study was to investigate if attitudes or behavioral beliefs about antiretroviral therapy (ART) influence ART adherence intention among pregnant and breastfeeding women in Zambia.

Methods: We recruited 150 HIV-positive women receiving ART in urban (Lusaka) and rural (Sinazongwe) districts of Zambia. Generalized modified Poisson regression models were used to assess the extent to which adherence intention was influenced by attitude toward ART or behavioral beliefs about ART.

Results: Intention to adhere to ART differed significantly by income, knowledge about HIV transmission, attitudes, and behavioral beliefs (all Ps <.05). In addition, strong intention to adhere to ART differed by urban (69\%) and rural (31\%) place of residence $(P \leq .01)$. In adjusted models, women in the weak adherence intention group were more likely to be older, have less knowledge about HIV transmission, and have a more negative attitude toward ART (PR 0.74; 95\% CI 0.67-0.82). Behavioral belief about ART, however, was significant in unadjusted model (PR 0.85; 95\% Cl 0.76-0.94) but not significant after adjusting for covariates such as age, knowledge of transmission, and district locality.
\end{abstract}

Conclusion: Compared to behavioral beliefs, attitudes about ART were more influential for intention to adhere. This knowledge will help inform effective and appropriate ART counseling for pregnant and breastfeeding women at different points along their ART time course.

Keywords: Theory of planned behavior, Rural, Pre-natal, Mother-to-child transmission, adherence intention, antiretroviral treatment

\section{Introduction}

There are approximately 85,000 HIV-positive children living in Zambia [1]. The source of infection is primarily through vertical transmission during pregnancy [2], childbirth [2] or breastfeeding from an HIV-positive mother [3, 4]. Administering antiretroviral (ARV) medication to childbearing

\footnotetext{
* Correspondence: jerry.nutor@ucsf.edu

${ }^{1}$ Family Health Care Nursing Department, School of Nursing, University of California, 2 Koret Way, Suite N431G, San Francisco, CA 94143-0608, USA Full list of author information is available at the end of the article
}

women who are HIV-positive is one effective strategy to eliminate vertical transmission; however, it requires adherence to the antiretroviral treatment (ART) $[5,6]$. Recent studies indicate low rates of adherence to ART among pregnant and breastfeeding women in sub-Saharan Africa [7-9]. In 2012, the World Health Organization (WHO) introduced treatment guidelines ("Option $\mathrm{B}+$ ") to reduce vertical transmission of HIV. Option B+ calls for triple ARV therapy (nevirapine, zidovudine and lamivudine) starting as soon as a woman tests positive for HIV and continuing for life

(c) The Author(s). 2020 Open Access This article is licensed under a Creative Commons Attribution 4.0 International License, which permits use, sharing, adaptation, distribution and reproduction in any medium or format, as long as you give appropriate credit to the original author(s) and the source, provide a link to the Creative Commons licence, and indicate if changes were made. The images or other third party material in this article are included in the article's Creative Commons licence, unless indicated otherwise in a credit line to the material. If material is not included in the article's Creative Commons licence and your intended use is not permitted by statutory regulation or exceeds the permitted use, you will need to obtain permission directly from the copyright holder. To view a copy of this licence, visit http://creativecommons.org/licenses/by/4.0/. The Creative Commons Public Domain Dedication waiver (http://creativecommons.org/publicdomain/zero/1.0/) applies to the data made available in this article, unless otherwise stated in a credit line to the data. 
regardless of CD4 count or viral load [10]. Option B+ was standard of care in Zambia until 2015, when the WHO expanded to a "90-90-90: Treatment for All" policy with the goal of diagnosing $90 \%$ of all people living with HIV, place $90 \%$ of diagnosed people on ART, and achieving 90\% viral suppression in treated people by 2020 .

After the introduction of Option B+, ARV drug use in pregnant and breastfeeding women in Zambia increased from $65 \%$ in 2013 to $80 \%$ in 2017 [11-13], yet adherence to treatment has been problematic. Data from a recent study conducted in Zambia among women enrolled in Option B+ indicate that $38 \%$ did not adhere to the ARV regimen [7]. Poor adherence to ART is related to factors that can be categorized as: patient-related (e.g., forgetting to take the medication or being too busy) [14], interpersonal (i.e. stigma and discrimination) [15], financial difficulty [14], health system (i.e. inaccessibility of services and relationships with service providers) $[9,16]$ and drug-related (i.e. side effects) $[7,13]$.

Poor adherence to ART can lead to reduced drug efficacy and increased risk of vertical transmission of HIV at an individual level, and lead to virologic failure [17], drug resistance [18], and vertical transmission [19] of resistant mutations at regional and global levels [14, 15]. Poor adherence can be intentional or unintentional [20, 21]. Unintentional non-adherence occurs when the patient intends to take the drug but circumstances such as forgetfulness, inadequate access to water or food, poor comprehension, or cost of medication limit adherence $[9,14,15,22]$. Intentional non-adherence occurs when the patient decides not to take a medication as recommended based on one's attitudes and beliefs [23, 24]. While unintentional non-adherence is common among patients receiving ART, intentional non-adherence has been increasing in low-resource countries [25-27].

According to the Theory of Planned Behavior (TPB) [21], a woman's intention to take ART is determined by her attitude toward the behavior (taking ARV drugs as prescribed) and her perceived control over the behavior $[20,21]$. Attitudes and beliefs influence motivation to start and continue ART [21, 23] and are influenced by education, religion, and socio-cultural norms [28]. In some low-resourced settings, for example, people may doubt the existence of HIV and therefore hesitate to get tested or initiate ART [29-32]. People who believe ART improves health are more likely to adhere to ART than people who have doubts about the disease itself or effectiveness of ARV drugs [23]. To improve ART adherence and reduce maternal-to-child transmission (MTCT), it is important to have a better understanding of childbearing women's intention to adhere to ART. As one of the top ten countries in the world with the highest prevalence of HIV, Zambia has over $80 \%$ of HIV positive pregnant and breastfeeding women currently receiving ART [12, 33]. However, attitudes and beliefs about ART associated with adherence intention has not been examined in Zambian HIV-positive childbearing women receiving ART.

Among TPB constructs, attitudes and behavioral beliefs receive the least attention in research on intention to adhere to ART among women at risk for transmitting the infection to their children [34, 35]. Therefore, the purpose of this study was to investigate how attitudes and behavioral beliefs about taking ART influence ART adherence intention among pregnant and breastfeeding women in Zambia. We hypothesized that positive attitude towards ART and positive behavioral beliefs about taking ART would predict strong adherence intention to ART.

\section{Methods \\ Design and sample}

This cross-sectional study of HIV-positive pregnant and breastfeeding women receiving ART took place in urban Lusaka district with predominantly Nyanja and Bemba ethnic groups, and rural Sinazongwe district with a predominantly Tonga ethnic group. The study sites included three hospitals in Lusaka district, and one hospital and two health centers in Sinazongwe district. The selected hospitals and health centers are the main designated clinics for pre- and post-natal care for women living with HIV in the respective districts. Using convenience sampling, we recruited women who received pre- and postnatal care at clinics in both districts. Women were eligible to participate if they were 18 years or older, on ART for at least 2 months, either pregnant or breastfeeding and not intellectually impaired or critically ill (defined as recent hospitalization). The protocol for this study was approved by Drexel University Institutional Review Board and two local institutional review boards: the Eres Converge Institutional Review Board and the Zambia National Health Research Authority.

Pregnant and breastfeeding women diagnosed with HIV infection were contacted in person when they arrived for a clinic visit to obtain their antiretroviral medication or to see their attending midwife or nurse for a regularly scheduled appointment. The midwife/nurse talked to potential participants about the study and women who agreed to learn more about the study were contacted by the trained research assistant. The research assistant explained the purpose, benefits and risks, and confidentiality to potential participants. A copy of the study's information sheet was given to women who could read. For women who could not read, the research assistant explained the information sheet in a language that the patient understood. After addressing any concerns or questions from potential participants, women who agreed to participate signed a consent form and self-administered questionnaires were distributed. If the 
participant could not read or write, questions were read in the language they understood best, and responses were recorded on the questionnaire by the research assistant.

\section{Measures \\ Overview}

The outcome and independent predictor variables for this study were adapted from the TPB [20, 21]. In this theory general items are suggested that can be adapted for specific clinical situations. The items underwent various revisions and pilot testing with 10 pregnant and breastfeeding women living with HIV. Results from the pilot test were used to finalize the questionnaire. The items were translated into two local languages (Tonga and Nyanja).

\section{Outcome variable: ART adherence intention}

In accordance with the TPB [19], adherence intention was measured with four items: (1) "I plan to take my medication consistently as prescribed by the healthcare provider", (2) "I intend to take my medication consistently as prescribed by the healthcare provider", (3) "I want to take my medication consistently as prescribed by the healthcare provider", and (4) "I will take my medication consistently as prescribed by the healthcare provider" [20]. Responses to these items followed a 5point Likert-type scale $(1=$ "strongly disagree", $2=$ "disagree", 3 = "in the middle", $4=$ "agree", $5=$ "strongly agree"). The four responses were summed to create an overall adherence intention score that could range from 4 to 20. Participants were then categorized as having weak adherence intention (score $<$ median of 17) or strong adherence intention (score $\geq 17$ ). Internal consistency reliability was acceptable in our sample (Cronbach $\alpha=0.80$ ).

\section{Independent predictor variables}

Attitude Attitude toward ART adherence was assessed with an 11-item questionnaire derived from the TPB [20] and included statements such as "Taking ART drugs is easy for me" and "It is tiresome to take MTCT drugs every day" which is reverse-coded [20]. Response options followed a 5-point Likert type scale (1= "strongly disagree" to $5=$ "strongly agree"), resulting in a possible range of 11 to 55 . The median score was used to categorize women as having a positive attitude toward ART $(\geq 48)$ or negative attitude toward ART $(<48)$. Internal consistency reliability was acceptable in our sample (Cronbach $\alpha=0.77)$.

Behavioral beliefs To measure behavioral beliefs about taking ART, four items derived from the TPB [20] were created: (1) "I am confident that I will take my ART drugs consistently as prescribed by my health care provider", (2) "My taking the ART drugs consistently as prescribed by the healthcare provider is useful to me", (3) "I feel comfortable about talking to my healthcare provider about taking my ART drugs", and (4) "If I take my ART drugs and experience side effects I will report to the healthcare provider". Response options were also on a 5point Likert-type scale $(1=$ "strongly disagree" to $5=$ "strongly agree"), with a possible range from 4 to 20 . Higher scores represent more positive beliefs and the median was used to categorize women into negative behavioral beliefs $(<12)$ or positive behavioral beliefs $(\geq 12)$. Internal consistency reliability was acceptable in our sample (Cronbach $\alpha=0.76$ ).

\section{Covariates}

\section{Knowledge about HIV transmission}

To examine knowledge about HIV maternal to child transmission (MTCT), a 13-item questionnaire from Ebuy and colleagues [22] was used with "true" or "false" responses about HIV and MTCT (e.g., "HIV-positive women can reduce the risk of HIV transmission to their babies if they take MTCT drugs", "Adhering to ARV drugs can reduce the risk of opportunistic infections"). The knowledge score can range from 0 to 13 , with higher scores representing a higher level of knowledge. Using the median score of 12 , participants were classified as either low $(<12)$ or high $(12-13)$ knowledge. Internal consistency reliability was acceptable in our sample (Cronbach $\alpha=0.75)$.

\section{Demographic characteristics}

he following characteristics were included based on the literature: place of residence (rural or urban) age, marital status (in a relationship living with partner, or in a relationship but not living with partner), education (no formal education or only primary education, secondary, or college and higher), employment (employed, housewife, or informal labor), and monthly household income (< US $\$ 200$ or $\geq$ US $\$ 200$ ).

\section{Data analysis}

Data entry and cleaning were done in SPSS version 24. Data were analyzed using STATA version 13 (College Station, TX). Descriptive statistics to summarize the variables included means and standard deviations (SD), medians and percentages. To examine adherence intention by the two independent variables, attitudes toward ART and beliefs about ART, bivariate analyses were conducted using modified Poisson regression models to estimate the unadjusted prevalence ratio (PR) and associated 95\% confidence interval (CI). In multivariate analyses, models for the two independent variables were 
built separately using a stepwise approach. Model 1 included attitude or behavioral beliefs, model 2 adjusted for socio-cultural place of residence (urban or rural district), model 3 adjusted for age, marital status, education, monthly household income and occupation in addition to district residence in model 2. Finally, model 4 adjusted for HIV and MTCT knowledge in addition to all the variables in model 3.

\section{Sensitivity analysis}

Because some researchers have operationalized behavioral intention as a continuous variable $[36,37]$ rather than categorical as we did in this study, we also conducted a sensitivity analyses to examine potential differences in findings based on how the concept of intention to adhere is operationalized. We performed unadjusted analysis and analyses for model 4 using adherence intention as a continuous variable.

\section{Results}

There were 81 (54\%) women from urban district and 69 (46\%) from rural district. The average age was 29 years $(\mathrm{SD}=6.2)$ and was similar in both urban and rural districts. The sample was socio-economically diverse; $85 \%$ were below the median monthly income of $\$ 200$ (US equivalent), and $55 \%$ had only primary or no formal education. The sample characteristics and results for bivariate analysis are presented in Table 1 by strong and weak intention to adhere groups. Of the 150 women who participated, 77 had strong intention to adhere and 73 were categorized as weak intention to adhere (Table 1). In bivariate analysis, the covariates significantly associated with adherence intention included place of residence $(p=0.01)$, income $(p=0.04)$, and scores for knowledge about HIV and MTCT $(p<0.001)$.

\section{Attitude toward ART}

In bivariate analysis, attitude toward ART was significantly $(\mathrm{p}<0.001)$ associated with adherence intention (Table 1). A majority (69\%) of women with a negative attitude toward ART were in the weak adherence intention group, and most (78\%) women with a positive attitude were in the strong adherence intention group.

In multivariate regression analysis, women with a negative attitude toward ART were less likely to be in the strong adherence intention group in unadjusted analysis (PR 0.73; 95\% CI 0.65-0.80) and this association remained consistent and significant in all adjusted analyses (Table 2). For example, in model 4 it can be seen that women with a negative attitude were less likely to be in the strong adherence intention group after adjusting for all other covariates (PR 0.74; 95\% CI 0.67-0.82). In addition, residential district remained significantly association with ART adherence intention in all the three adjusted analyses. Age and level of knowledge were also significantly associated with adherence intention in the final adjusted analysis (model 4); indicating that women 26-30 years old were less likely to be in the strong adherence intention group than younger women 18-25 years old (PR 0.85; 95\% CI 0.74-0.96), and women with less knowledge were also less likely to be in the strong adherence intention group (PR 0.90; 95\% CI 0.80-1.00).

\section{Behavioral beliefs about ART}

In bivariate analysis, behavioral belief score was significantly associated with adherence intention $(p<0.01)$. A majority (63\%) of the women with negative beliefs about ART were in the weak adherence intention group and a similar percentage $(62 \%)$ of women with positive beliefs were in the strong adherence intention group (Table 1).

The multivariate analyses for behavioral beliefs about ART and adherence intention are presented in Table 3. Although behavioral belief about ART was significantly associated with adherence intention in unadjusted analysis (PR 0.85; 95\% CI 0.76-0.94), the association was no longer significant after adjusting for residential district (model 2) or age and other covariates (model 3).

In the final model, residential district, age and knowledge remained significant. Rural women were $15 \%$ less likely to be in the strong adherence intention group compared to urban women (PR 0.85; 95\% CI 0.73-0.99). Women 26-30 years old were less likely to be in the strong adherence intention group than younger women 18-25 years old (PR 0.85; 95\% CI 0.73-1.00), and women with less knowledge were also less likely to be in the strong adherence intention group (PR 0.86; 95\% CI 0.76-0.98).

\section{Discussion}

In this study, the TPB was used for the first time as a framework for examining ART adherence intention among HIV-positive childbearing women in Zambia. In bivariate analysis, both attitude toward ART and behavioral beliefs about ART were significantly associated with adherence intention. However, the adjusted models for adherence intention showed a significant association with attitude but not beliefs, and in general, older rural women with less knowledge were less likely to be in the strong adherence group.

According to the TPB, medication adherence is predicted from intention to adhere, which is grounded in one's attitudes and beliefs [20]. Attitudes and beliefs are inter-related concepts heavily influenced by one's sociocultural environment, but after adjusting for residential district and other factors in our sample, it was attitudes rather than beliefs that were associated with intention to adhere to ART for Zambian women enrolled in the Option B+ treatment regimen. 
Table 1 Adherence Intention to ART in Childbearing Women in Zambia ( $N=150)$

\begin{tabular}{|c|c|c|c|}
\hline Characteristics & $\begin{array}{l}\text { Weak Intention } \\
\text { n (\%) }\end{array}$ & $\begin{array}{l}\text { Strong Intention } \\
\text { n (\%) }\end{array}$ & $\begin{array}{l}\text { Chi-square } \\
P \text { value }\end{array}$ \\
\hline Place of residence & & & 0.01 \\
\hline Urban & $28(38)$ & $53(69)$ & \\
\hline Rural & $45(62)$ & $24(31)$ & \\
\hline Age, years & & & 0.15 \\
\hline $18-25$ & $11(15)$ & $23(30)$ & \\
\hline $26-30$ & $33(45)$ & $25(32)$ & \\
\hline $31-35$ & $17(23)$ & $17(22)$ & \\
\hline $36-44$ & $12(16)$ & $12(16)$ & \\
\hline Living arrangement & & & 0.35 \\
\hline Married not living with partner & $9(12)$ & $6(8)$ & \\
\hline Married, living with partner & $64(88)$ & $71(92)$ & \\
\hline Educational status & & & 0.44 \\
\hline Primary or no formal education & $44(60)$ & $39(51)$ & \\
\hline Secondary & $25(32)$ & $31(40)$ & \\
\hline College/Higher & $4(5)$ & $7(9)$ & \\
\hline Occupation & & & 0.35 \\
\hline Employed & $16(22)$ & $25(32)$ & \\
\hline Housewife & $36(49)$ & $33(43)$ & \\
\hline Informal labor & $21(29)$ & $19(25)$ & \\
\hline Household monthly income & & & 0.04 \\
\hline$<\$ 200$ & $66(90)$ & $59(77)$ & \\
\hline$\$ 200+$ & $7(10)$ & $18(23)$ & \\
\hline Attitude & & & $<0.001$ \\
\hline Negative & $50(69)$ & $17(22)$ & \\
\hline Positive & $23(31)$ & $60(78)$ & \\
\hline Behavioral Beliefs & & & 0.01 \\
\hline Negative & $46(63)$ & $29(38)$ & \\
\hline Positive & $27(37)$ & $48(62)$ & \\
\hline HIV and MTCT knowledge & & & 0.01 \\
\hline Low & $64(88)$ & $48(62)$ & \\
\hline High & $9(12)$ & $29(38)$ & \\
\hline
\end{tabular}

In our sample of women at risk for MTCT of their HIV infection, positive attitudes and beliefs were associated with strong adherence intention. Other researchers have used the TPB to explain health behaviors [38-40]. In fact, results from a meta-analysis of research utilizing the TPB framework indicated that the TPB could be used to predict $39 \%$ of the variance in intention and only $27 \%$ of the variance in behavior [41]. Additional studies, therefore, are needed to continue this type of research specifically focused on intention to adhere as a predictor of actual ART adherence behavior.

When Chisholm and colleagues [42] used the TPB to predict adherence to immunosuppressant therapy in renal transplant patients, they found discrepancies in the way the TPB model operated and raised questions about using it to study complex behaviors such as adherence to long-term medication regimens. Similar conclusions were reported by Pellino [43] who used the TPB to investigate analgesic use in adults after elective orthopedic surgery. However, in a sample of Latino HIV-positive adults, Vissman and colleagues [44] found that all components of TPB were significant in predicting adherence to highly active ART. Therefore, for research in this area to progress, further effort is necessary to design valid and reliable measures of the TPB components for specific applications, such as predicting adherence behavior.

Despite the fact that not all the components of the TPB were statistically significant in this study, the results 
Table 2 Multiple Regression Models for Adherence Intention Associated with Attitude Toward ART $(N=150)$

\begin{tabular}{|c|c|c|c|c|}
\hline \multirow[t]{2}{*}{ Characteristics } & Model 1 & Model 2 & Model 3 & Model 4 \\
\hline & PR $(95 \% \mathrm{Cl})$ & PR (95\% Cl) & PR $(95 \% \mathrm{Cl})$ & PR $(95 \% \mathrm{Cl})$ \\
\hline \multicolumn{5}{|l|}{ Attitude toward ART } \\
\hline Positive & Referent & Referent & Referent & Referent \\
\hline Negative & $0.73(0.65-0.80) * *$ & $0.74(0.68-0.81)^{* *}$ & $0.73(0.66-0.81)^{* *}$ & $0.74(0.67-0.82)^{* *}$ \\
\hline \multicolumn{5}{|l|}{ District } \\
\hline Urban & & Referent & Referent & Referent \\
\hline Rural & & $0.84(0.77-0.92) * *$ & $0.85(0.76-0.95)^{* *}$ & $0.86(0.77-0.96)^{*}$ \\
\hline \multicolumn{5}{|l|}{ Age } \\
\hline $18-25$ & & & Referent & Referent \\
\hline $26-30$ & & & $0.84(0.74-0.95)^{*}$ & $0.85(0.74-0.96)^{*}$ \\
\hline $31-35$ & & & $0.88(0.76-1.02)$ & $0.90(0.77-1.04)$ \\
\hline $36-44$ & & & $0.93(0.80-1.09)$ & $0.94(0.80-1.10)$ \\
\hline \multicolumn{5}{|l|}{ Living arrangement } \\
\hline Married living with partner & & & Referent & Referent \\
\hline Married, not living with partner & & & $0.93(0.79-1.10)$ & $0.95(0.80-1.12)$ \\
\hline \multicolumn{5}{|l|}{ Educational status } \\
\hline College/Higher & & & Referent & Referent \\
\hline Primary or no formal education & & & $0.94(0.76-1.16)$ & $0.97(0.79-1.20)$ \\
\hline Secondary & & & $0.92(0.75-1.12)$ & $0.94(0.77-1.16)$ \\
\hline \multicolumn{5}{|l|}{ Occupation } \\
\hline Employed & & & Referent & Referent \\
\hline Housewife & & & $0.98(0.86-1.11)$ & $1.00(0.87-1.13)$ \\
\hline Informal labor & & & $0.98(0.85-1.14)$ & $1.00(0.86-1.16)$ \\
\hline \multicolumn{5}{|l|}{ Household monthly Income } \\
\hline$\$ 200+$ & & & Referent & Referent \\
\hline$<\$ 200$ & & & $0.91(0.78-1.05)$ & $0.92(0.79-1.07)$ \\
\hline \multicolumn{5}{|l|}{ HIV and MTCT knowledge } \\
\hline High & & & & Referent \\
\hline Low & & & & $0.90(0.80-1.00)^{*}$ \\
\hline
\end{tabular}

are clinically informative, particularly for health care providers who work in more rural settings. Our findings indicate that women with more negative attitudes and behavioral beliefs about ART are less likely to have a strong intention to adhere to ART. These findings have research implications for designing and testing interventions to enhance patient adherence intention and subsequent adherence to ART. Interventions that specifically target women's negative attitudes and behavioral beliefs about ART should effectively increase adherence to Option B+. Such interventions, however, should be tailored to individual adherence risk according to the TPB components that provide direction in implementing strategies to foster more positive attitudes and beliefs towards Option $\mathrm{B}+$
. Such interventions would ultimately improve overall adherence rates with Option B+.

Our findings also have important policy implications, given that attitude and behavioral beliefs about ART influenced adherence intention among childbearing women in both rural and urban settings. Information about HIV and transmission to the infant should be presented to women prior to initiating ART treatment, and women should be given sufficient time to acknowledge the importance of this information for their own health and the health of entire family. In addition, health educators can use our findings to advocate for appropriate educational programs and materials that reach more vulnerable populations, especially in more rural and lowresourced areas. 
Table 3 Multiple Regression Model for Adherence Intention Associated with Behavioral Beliefs About ART $(N=150)$

\begin{tabular}{|c|c|c|c|c|}
\hline \multirow[t]{2}{*}{ Characteristics } & Model 1 & Model 2 & Model 3 & Model 4 \\
\hline & PR $(95 \% \mathrm{Cl})$ & PR $(95 \% \mathrm{Cl})$ & PR $(95 \% \mathrm{Cl})$ & PR $(95 \% \mathrm{Cl})$ \\
\hline \multicolumn{5}{|l|}{ Behavioral beliefs about ART } \\
\hline Positive & Referent & Referent & Referent & Referent \\
\hline Negative & $0.85(0.76-0.94)^{* *}$ & $0.93(0.82-1.09)$ & $0.91(0.79-1.06)$ & $0.92(0.80-1.06)$ \\
\hline \multicolumn{5}{|l|}{ District } \\
\hline Urban & & Referent & Referent & Referent \\
\hline Rural & & $0.85(0.74-0.97)^{*}$ & $0.82(0.72-0.98)^{*}$ & $0.85(0.73-0.99)^{*}$ \\
\hline \multicolumn{5}{|l|}{ Age, years } \\
\hline $18-25$ & & & Referent & Referent \\
\hline $26-30$ & & & $0.86(0.74-0.99)^{*}$ & $0.85(0.73-1.00)^{*}$ \\
\hline $31-35$ & & & $0.92(0.78-1.08)$ & $0.94(0.80-1.10)$ \\
\hline $36-44$ & & & $0.92(0.77-1.09)$ & $0.93(0.78-1.11)$ \\
\hline \multicolumn{5}{|l|}{ Living arrangement } \\
\hline Married, living with a partner & & & Referent & Referent \\
\hline Married, not living with partner & & & $0.90(0.75-1.09)$ & $0.92(0.77-1.11)$ \\
\hline \multicolumn{5}{|l|}{ Educational status } \\
\hline Higher/College & & & Referent & Referent \\
\hline Primary or no formal education & & & $0.92(0.73-1.17)$ & $0.97(0.76-1.23)$ \\
\hline Secondary & & & $0.93(0.74-1.16)$ & $0.96(0.77-1.21)$ \\
\hline \multicolumn{5}{|l|}{ Occupation } \\
\hline Employed & & & Referent & Referent \\
\hline Housewife & & & $0.90(0.78-1.04)$ & $0.92(0.79-1.07)$ \\
\hline Informal labor & & & $1.01(0.86-1.20)$ & $1.02(0.87-1.22)$ \\
\hline \multicolumn{5}{|l|}{ Household monthly income } \\
\hline$\$ 200+$ & & & Referent & Referent \\
\hline$<\$ 200$ & & & $0.94(0.80-1.11)$ & $0.95(0.81-1.13)$ \\
\hline \multicolumn{5}{|l|}{ HIV and MTCT knowledge } \\
\hline High & & & & Referent \\
\hline Low & & & & $0.86(0.76-0.98)^{*}$ \\
\hline
\end{tabular}

${ }^{*} p$ value $\leq 0.05$

${ }^{* *} p$ value $\leq 0.01$

The results of this study would be particularly helpful to both clinicians and public health officials because these insights about attitudes and beliefs may be useful in improving adherence intention by paying particular attention to rural communities where socio-cultural resources and knowledge about HIV transmission may be less available. By extension, interventions can be developed and tested to specifically address these negative attitudes and beliefs to promote ART adherence.

\section{Limitations}

Although our findings contribute to a more comprehensive understanding of factors that influence women's adherence intention to improve health and prevent vertical transmission of HIV to their child, this was a cross- sectional study and it is important to note that these associations are not proof of causation. It is also important to note that all measures in the current study were selfreported. Like all self-report data, some responses might be biased toward social desirability, particularly when a survey is administered face-to-face. The cross-sectional design also does not provide evidence about whether women with a stronger intention to adhere to ART had subsequently better adherence to ART compared to women with a weaker intention. However, evidence from a systematic review indicated that intentions are predictive of subsequent adherence to ART [45]. Furthermore, while data were collected from both a rural and urban district in Zambia, findings may not generalize to all women in Zambia or sub-Saharan 
Africa. The participants in this study were from a rural part of the Southern Province and the urban part of Lusaka Province, which are culturally and ethnically different from other parts of Zambia. It remains unknown whether our findings regarding attitude and perceived beliefs would be observed in childbearing women from other ethnic groups in Zambia. Finally, while vertical transmission is possible for both pregnant and breastfeeding women, we did not compare these two groups and our results may be influenced by maternal events that occur before or after giving birth.

\section{Conclusions}

Findings from this study suggest that the TPB, specifically attitudes more so than beliefs, can help elucidate key dynamics for improving adherence to ART among Zambian childbearing women. As expected, the theoretical constructs of attitudes and behavioral beliefs were related to intention to adhere to ART Although others have used the TPB to guide their research, measures have largely focused only on attitude, perceived behavioral control, or perceived self-efficacy, and have not addressed specific beliefs related to ART intention. In our present study, negative attitudes and behavioral beliefs were identified as potentially important mediators that should be targeted for interventions designed to increase ART adherence. Future research should be designed to extend the generalizability of our findings to Zambian women of different ethnicities. In light of documented barriers to adherence to ART among Zambian women, the TPB provides a potentially useful framework for researchers and clinicians interested in interventions to increase adherence to ART.

\section{Abbreviations \\ AIDS: Acquired Immune Deficiency Syndrome; ART: Antiretroviral Therapy; ARV: Antiretroviral; MTCT: Mother-to-child transmission; HIV: Human Immunodeficiency Virus; PR: Prevalence ratio; TPB: Theory of Planned Behavior; WASH: Water Hygiene and Sanitation; WHO: World Health Organization}

\section{Acknowledgements}

We would like to extend our gratitude to the Dornsife Global development Scholars program at Drexel University and World Vision Zambia staff who supported this project. We would also like to thank Dr. Kathryn Lee and Dr. Julene K. Johnson for editing the manuscript.

\section{Authors' contributions}

JJN participated in the design of the research protocols, trained local staff on research protocols, analyzed all the research data and participated in the drafting of the manuscript. JCS participated in the design of the research protocol, drafting of the manuscript and sought ethical approval at Drexel University. SM participated in research protocol, drafting of the manuscript and mobilized funding for the project. RAD participated in the design of the research protocol and drafting of the manuscript. FM participated in research design of the research protocol drafting of the manuscript. LSJ and KEO participated in designing the research protocol and drafting the manuscript. All authors read and approved the final manuscript.

\section{Funding}

This study was funded by Dornsife Global Development Scholar Program, Drexel University as a dissertation grant to the first author. Additional funding was provided by School of Nursing, University of California, San Francisco.

\section{Availability of data and materials}

The datasets generated and/or analyzed during the current study are available from the corresponding author on reasonable request.

\section{Ethics approval and consent to participate}

The protocol for this study was approved by Drexel University Institutional Review Board with approval number 1706005436 and two local institutional review boards: the ERES Converge Institutional Review Board number 2017 Apr-011 and the Zambia National Health Research Authority number MH/ 101/23/10/1. Participants gave consent prior to enrollment using consent forms approved by Drexel University Institutional Review Board, ERES Converge Institutional Review Board and Zambia National Health Research Authority. Interested adult pregnant and breastfeeding women aged 18 and above were enrolled in the study after signing a standardized consent form.

\section{Consent for publication}

Not applicable.

\section{Competing interests}

The authors declare that they have no competing interests.

\section{Author details}

${ }^{1}$ Family Health Care Nursing Department, School of Nursing, University of California, 2 Koret Way, Suite N431G, San Francisco, CA 94143-0608, USA. ${ }^{2}$ Division of Epidemiology and Community Health, University of Minnesota, Minneapolis, MN 55454, USA. ${ }^{3}$ Undergraduate Global Engagement, Columbia University, New York City, NY 110027, USA. ${ }^{4}$ College of Nursing and Health Professions, Drexel University, Philadelphia, PA 19104, USA. ${ }^{5}$ Department of Medicine, Hospital of University of the Pennsylvania, Philadelphia, PA 19102 , USA. ${ }^{6}$ Department of Public Health, Faculty of Health Sciences, University of Fort Hare, Alice, Eastern Cape, South Africa.

Received: 6 April 2020 Accepted: 6 September 2020

Published online: 16 September 2020

\section{References}

1. HIV and AIDS [https://www.unicef.org/zambia/5109 8459.html].

2. Kourtis AP, Bulterys M, Nesheim SR, Lee FK. Understanding the timing of HIV transmission from mother to infant. J Am Med Assoc. 2001;285(6):70912

3. Embree JE, Njenga S, Datta P, Nagelkerke NJ, Ndinya-Achola JO, Mohammed Z, Ramdahin S, Bwayo JJ, Plummer FA. Risk factors for postnatal mother-child transmission of HIV-1. J Acquir Immune Defic Syndr. 2000;14(16):2535-41.

4. Tubiana R, Le Chenadec J, Rouzioux C, Mandelbrot L, Hamrene K, Dollfus C, Faye A, Delaugerre C, Blanche S, Warszawski J. Factors associated with mother-to-child transmission of HIV-1 despite a maternal viral load $<500$ copies/ml at delivery: a case-control study nested in the French perinatal cohort (EPF-ANRS CO1). Clin Infect Dis. 2010;50(4):585-96.

5. Ogundele M, Coulter J: HIV transmission through breastfeeding: problems and prevention. Annals of Tropical Paediatrics: International Child Health 2013

6. World Health Organization. Use of Antiretroviral Drugs for Treating Pregnant Women and Preventing HIV Infection in Infants. Geneva: World Health Organization; 2012.

7. Nutor JJ, Slaughter-Acey JC, Marquez S, Opong E. Factors associated with HIV medication adherence in HIV-positive women enrolled in option B+ in Zambia: a cross-sectional survey. Lancet Glob Health. 2019;7:S7.

8. Nachega JB, Uthman OA, Anderson J, Peltzer K, Wampold S, Cotton MF, Mills EJ, Ho Y-S, Stringer JS, McIntyre JAJA. Adherence to antiretroviral therapy during and after pregnancy in low-, middle and high income countries: a systematic review and meta-analysis. 2012;26(16):2039.

9. Hodgson I, Plummer ML, Konopka SN, Colvin CJ, Jonas E, Albertini J, Amzel A, KPJPO F. A systematic review of individual and contextual factors 
affecting ART initiation, adherence, and retention for HIV-infected pregnant and postpartum women. 2014;9(11):e111421.

10. Malawi's Option B+ programme is helping to eliminate mother-to-child transmission of HIV [https://www.unicef.org/infobycountry/malawi_70997. html].

11. Prevention of mother-to-child transmission (PMTCT) [https://www.who.int/ gho/hiv/epidemic_response/PMTCT_text/en/].

12. HIV/AIDS: Data and Statistics [https://www.who.int/hiv/data/en/].

13. Nutor JJ, Slaughter-Acey JC, Marquez SP, DiMaria-Ghalili RA, Momplaisir F, Jemmott LS. Influence of toilet access on antiretroviral adherence intention among pregnant and breastfeeding women who are HIV-positive and enrolled in option B+: Health Care for Women International; 2020. p. 1-15.

14. Knettel BA, Cichowitz C, Ngocho JS, Knippler ET, Chumba LN, Mmbaga BT, Watt MH. Retention in HIV care during pregnancy and the postpartum period in the option B+ era: systematic review and meta-analysis of studies in Africa: NIH Public Access; 2018.

15. Kiwanuka G, Kiwanuka N, Muneza F, Nabirye J, Oporia F, Odikro MA, Castelnuovo B, Wanyenze RK. Retention of HIV infected pregnant and breastfeeding women on option B+ in Gomba District, Uganda: a retrospective cohort study. BMC Infect Dis. 2018;18(1):533.

16. Kaplan R, Orrell C, Zwane E, Bekker L-G, RJA W. Loss to follow-up and mortality amongst pregnant women referred to a community clinic for antiretroviral treatment. 2008:22(13):1679.

17. Koss CA, Natureeba P, Kwarisiima D, Ogena M, Clark TD, Olwoch P, Cohan D, Okiring J, Charlebois ED, MRJJoaids K. Viral suppression and retention in care up to 5 years after initiation of lifelong ART during pregnancy (option B+) in rural Uganda. 2017;74(3):279.

18. Nachega JB, Sam-Agudu NA, Mofenson LM, Schechter M, Mellors JW. Achieving viral suppression in $90 \%$ of people living with HIV on antiretroviral therapy in low-and middle-income countries: progress, challenges, and opportunities. Clin Infect Dis. 2018;66(10):1487-91.

19. Bezabhe WM, Chalmers L, Bereznicki LR, Peterson GMJM. Adherence to antiretroviral therapy and virologic failure: a meta-analysis. 2016;95(15).

20. Aizen I. From intentions to actions: a theory of planned behavior. In: Action control: Springer; 1985. p. 11-39.

21. Aizen I. Perceived behavioral control, self-efficacy, locus of control, and the theory of planned behavior. J Appl Soc Psychol. 2002;32(4):665-83.

22. Ebuy $\mathrm{H}$, Yebyo $\mathrm{H}$, Alemayehu M. Level of adherence and predictors of adherence to the option B+ PMTCT programme in Tigray, northern Ethiopia. Int J Infect Dis. 2015:33:123-9.

23. Boateng D, Kwapong GD, Agyei-Baffour P. Knowledge, perception about antiretroviral therapy (ART) and prevention of mother-to-child-transmission (PMTCT) and adherence to ART among HIV positive women in the Ashant region, Ghana: a cross-sectional study. BioMed Centra Women's Health. 2013;13(1):1.

24. Senkomago V, Guwatudde D, Breda M, Khoshnood K. Barriers to antiretroviral adherence in HIV-positive patients receiving free medication in Kayunga, Uganda. J Acquir Immune Defic Syndrome Care. 2011;23(10): 1246-53.

25. Mo PK, Mak WW. Intentionality of medication non-adherence among individuals living with HIV/AIDS in Hong Kong. AIDS Care. 2009;21(6):78595.

26. Kamuhabwa A, Bakari M. The magnitude of intentional non-adherence to antiretroviral therapy among patients attending HIV care and treatment clinic at Muhimbili National Hospital, Dar es Salaam, Tanzania. Tanzania Med J. 2009;24(2)

27. Kalichman S, Mathews C, Banas E, Kalichman M. Alcohol-related intentional nonadherence to antiretroviral therapy among people living with HIV, Cape Town, South Africa. AIDS Care. 2019;31(8):951-7.

28. Jemmott JB, Jemmott LS, Braverman P, Fong G. HIV/STD risk reduction interventions for African American and Latino adolescent girls at an adolescent medicine clinic: a randomized controlled trial. Arch Pediatr Adolesc Med. 2005;159(5):440-9.

29. Deribew A, Abebe G, Apers L, Jira C, Tesfaye M, Shifa J, Abdisa A, Woldemichael K, Deribie F, Bezabih M. Prejudice and misconceptions about tuberculosis and HIV in rural and urban communities in Ethiopia: a challenge for the TB/HIV control program. BMC Public Health. 2010;10(1): 400.

30. Yaya S, Ghose B, Udenigwe O, Shah V, Hudani A, Ekholuenetale M. Knowledge and attitude of HIV/AIDS among women in Nigeria: a crosssectional study. Eur J Pub Health. 2018;29(1):111-7.
31. Gazimbi MM, Magadi MA. Individual-and community-level determinants of antenatal hiv testing in Zimbabwe. J Biosoc Sci. 2019:51(2):203-24.

32. Nutor JJ, Duah HO, Agbadi P, Duodu PA, Gondwe KW. Spatial analysis of factors associated with HIV infection in Malawi: indicators for effective prevention. BMC Public Health. 2020;20(1):1167.

33. HIV/AIDS [http://www.who.int/mediacentre/factsheets/fs360/en/].

34. Senkowski V, Gannon C, Branscum P. Behavior change techniques used in theory of planned behavior physical activity interventions among older adults: a systematic review. J Aging Phys Act. 2019;27(5):746-54

35. Saal W, Kagee A. The applicability of the theory of planned behaviour in predicting adherence to ART among a south African sample. J Health Psychol. 2012;17(3):362-70

36. Jalilian F, Mirzaei-Alavijeh M, Ahmadpanah M, Mostafaei S, Kargar M Pirouzeh R, Sadeghi Bahmani D, Brand S. Extension of the Theory of Planned Behavior (TPB) to predict patterns of marijuana use among young Iranian adults. Int J Environ Res Public Health. 2020;17(6).

37. Zhu G, Qian X, Qi L, Xia C, Ming Y, Zeng Z, Liu Y, Yang Y, Zhang M, Zhang $\mathrm{H}$. The intention to undertake physical activity in pregnant women using the theory of planned behaviour. J Adv Nurs. 2020.

38. Johnston KL, White KM. Binge-drinking: a test of the role of group norms in the theory of planned behaviour. Psychol Health. 2003;18(1):63-77.

39. Villarruel AM, Jemmott JB III, Jemmott LS, Ronis DL. Predictors of sexual intercourse and condom use intentions among Spanish-dominant Latino youth: a test of the planned behavior theory. Nurs Res. 2004;53(3):172-81.

40. Jemmott JB III, Heeren G, Ngwane Z, Hewitt N, Jemmott L, Shell R, O'leary A. Theory of planned behaviour predictors of intention to use condoms among Xhosa adolescents in South Africa. AIDS Care. 2007;19(5):677-84

41. Armitage CJ, Conner M. Efficacy of the theory of planned behaviour: a meta-analytic review. Br J Soc Psychol. 2001;40(4):471-99.

42. Chisholm MA, Williamson GM, Lance CE, Mulloy LL. Predicting adherence to immunosuppressant therapy: a prospective analysis of the theory of planned behaviour. Nephrol Dialysis Transplant. 2007;22(8):2339-48.

43. Pellino TA. Relationships between patient attitudes, subjective norms, perceived control, and analgesic use following elective orthopedic surgery. Res Nurs Health. 1997:20(2):97-105.

44. Vissman AT, Hergenrather KC, Rojas G, Langdon SE, Wilkin AM, Rhodes SD Applying the theory of planned behavior to explore HAART adherence among HIV-positive immigrant Latinos: elicitation interview results. Patient Educ Couns. 2011;85(3):454-60

45. Rich A, Brandes K, Mullan B, Hagger MS. Theory of planned behavior and adherence in chronic illness: a meta-analysis. J Behav Med. 2015;38(4):673-88.

\section{Publisher's Note}

Springer Nature remains neutral with regard to jurisdictional claims in published maps and institutional affiliations.

Ready to submit your research? Choose BMC and benefit from:

- fast, convenient online submission

- thorough peer review by experienced researchers in your field

- rapid publication on acceptance

- support for research data, including large and complex data types

- gold Open Access which fosters wider collaboration and increased citations

- maximum visibility for your research: over $100 \mathrm{M}$ website views per year

At BMC, research is always in progress.

Learn more biomedcentral.com/submissions 